\title{
Investment Risk Management at Mining Enterprises
}

\author{
Victoria Frolova $^{1, *}$, Olga Dolina $^{1}$, and Tatyana Shpilkina ${ }^{2}$ \\ ${ }^{1}$ Financial University under the Government of the Russian Federation, 125993 Leningradsky \\ Prospekt 49, Moscow, Russia, \\ ${ }^{2}$ Moscow Automobile and Road Construction State Technical University (MADI), 125319 \\ Leningradsky prospect 64, Moscow, Russia
}

\begin{abstract}
The development of the Russian economy requires an increase in production factors, including energy, fuel and raw materials. Sustainable functioning of mining enterprises has an impact on the development of such industries as metallurgy, engineering, road construction and predetermines the development of the country's economy as a whole. The article substantiates the need to form an investment risk management system in the mining industry to encourage expansion of environmentsaving measures funding. The stages of investment risk management are proposed and their content is disclosed. The most significant types of investment risks and uncertainties in assessing geological exploration investment projects in the mining industry are considered. The recommendations for considering the factors of uncertainty and risk when evaluating the effectiveness of environmental and geological exploration investment projects to use maximum information about the conditions for the implementation of projects. For risk assessment, various qualitative and quantitative methods have been proposed, and the advantages of the Monte-Carlo simulation method are shown.
\end{abstract}

\section{Introduction}

For the reproduction of the mineral resource base, significant investments are needed for geological exploration, development and implementation of investment projects. Such projects in the development of the mining industry are aimed, as a rule, for a long period from 5 to 10 years or more. They are characterized by high capital intensity, due to the need to purchase expensive equipment and vehicles, install large buildings and structures. The long duration of the development and implementation of the project necessitates taking into account the high degree of uncertainty in the macroeconomic situation, the trends in the global markets, since during this period there can be significant changes in market conditions, sources and amounts of project financing. The state, whose revenues depend on the efficiency of the functioning of the mineral resource complex, and mining enterprises in particular, are interested in creating conditions that are attractive for investors in mining and environmental activity.

\footnotetext{
*Corresponding author: academy@,fa.ru
} 


\section{Materials and Methods}

Investments in mining industry are usually associated with greater risks and uncertainty than in other industries. This is primarily due to the specifics of the industry in which there are risks associated with the non-confirmation of mineral reserves, determined by geological exploration; deterioration of mining and geological conditions in the course of mining; decrease in the content of useful components in the extracted raw materials. In this regard, the study of investment risks and their management system in the mining industry in conditions of uncertainty is highly relevant [1-2]. Stages of investment risk management can be represented in the form of the following scheme (Fig. 1).

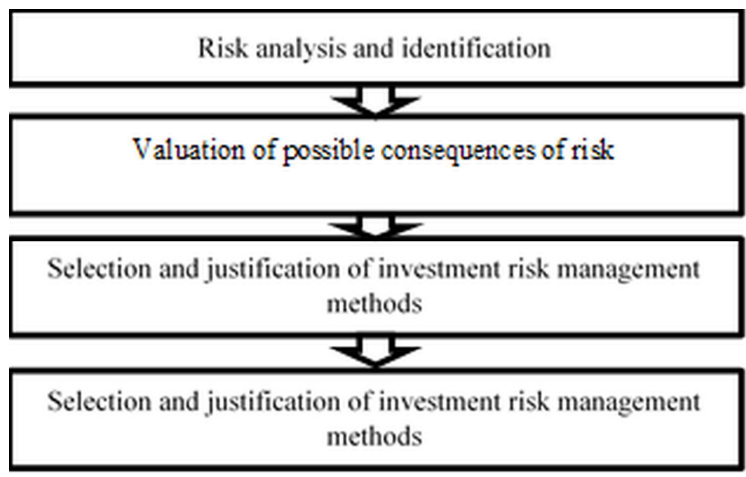

Fig. 1. Stages of investment risk management.

Risk is understood as the possibility of a situation arising in the process of implementing an investment project that will lead to adverse consequences for project participants. Uncertainty means the absence or unavailability of complete and reliable information about the conditions for the implementation of an investment project.

\section{Results and Discussion}

In the post-crisis period, the economy needs an influx of resources for its development. In recent years, investment in mining has continued to increase. Tab.1 shows the volume of investment in mining and their dynamics for 2016-2017.

Table 1. Capital investments in mining in the Russian Federation in 2017 [3].

\begin{tabular}{|c|c|c|c|}
\hline Mining of raw materials & $\begin{array}{c}\text { Investments } \\
\text { in fixed } \\
\text { assets, billion } \\
\text { rubles }\end{array}$ & $\begin{array}{c}\text { As a percentage of } \\
\text { the total investment } \\
\text { in the country's } \\
\text { economy for the year }\end{array}$ & $\begin{array}{c}\text { As a percentage of } \\
\mathbf{2 0 1 6}\end{array}$ \\
\hline Mining operations, of which: & 2936.7 & 24.0 & 108.6 \\
\hline coal mining & 116.5 & 1.0 & 127.8 \\
\hline $\begin{array}{c}\text { crude oil and natural gas } \\
\text { production }\end{array}$ & 1776.9 & 14.5 & 113.4 \\
\hline metal ore mining & 174.7 & 1.4 & 112.0 \\
\hline mining of other minerals & 51.6 & 0.4 & 91.0 \\
\hline
\end{tabular}

As follows from the data in Tab. 1, investment in fixed assets of organizations engaged in the extraction of minerals increased by $8.6 \%$ in 2017 , with a higher growth rate of investment in coal mining - an increase in investment in 2017 was $27.8 \%$, as a percentage of the total investment in the country's economy for the year, it was only $1 \%$, which is 
explained by the theory of opportunity costs, competition in the investment market and the possibility of using other types of fuel and energy resources.

Table 2 presents the results of economic activities of organizations engaged in mining in the dynamics for 2016-2017.

Table 2. Turnover of organizations by economic activity, billion rubles [3].

\begin{tabular}{|c|c|c|c|c|}
\hline Mining of raw materials & $\mathbf{2 0 1 6}$ & $\mathbf{2 0 1 7}$ & $\begin{array}{c}\text { Growth rate } \\
\mathbf{2 0 1 7 / 2 0 1 6 , \%}\end{array}$ & $\begin{array}{c}\text { Product } \\
\text { profitability in } \\
\mathbf{2 0 1 7} \mathbf{\%}\end{array}$ \\
\hline $\begin{array}{c}\text { Turnover of organizations - } \\
\text { total }\end{array}$ & 146376.8 & 158778.0 & 108.47 & 6.7 \\
\hline mining operations, of which: & 11688.3 & 13708.3 & 117.28 & 24.6 \\
\hline coal mining & 967.3 & 1324.9 & 136.97 & 28.4 \\
\hline $\begin{array}{c}\text { crude oil and natural gas } \\
\text { production }\end{array}$ & 7700.7 & 9064.6 & 117.71 & 24.1 \\
\hline metal ore mining & 968.3 & 1071.5 & 110.66 & 47.4 \\
\hline mining of other minerals & 621.5 & 571.7 & 91.99 & 41.5 \\
\hline
\end{tabular}

From Tab. 2 it follows that for the years under consideration the growth rate of turnover of organizations engaged in mining operations was $17.28 \%$, which is higher than the average turnover growth rate for all organizations in the economy $-8.47 \%$. This indicates the presence of demand for the products of the industry, expansion of the scale of production and the need for further investment in its development to ensure economic growth at the macroeconomic level.

The actual problem of mining companies is a thorough study of investment projects, risk assessment and investment risk management. Investments in the extractive industry are expensive projects that require significant costs over a long period of time and are associated with various types of risks. That is, "... development and implementation of programs for the development of mining regions and their environmental safety requires substantial financial costs" [2]. High capital intensity and long-term projects leads to the need to use borrowed resources, which causes the risk of losing control over the management of the company in the event of default on loans.

Studies show that one of the factors hindering investment activity is the presence of significant investment risks, as shown on Tab. 3, on Fig. 2.

Table 3. Assessment of factors hindering investment activity in the Russian Federation (in\% of the total number of organizations) [3].

\begin{tabular}{|c|c|c|c|c|c|}
\hline $\begin{array}{c}\text { Barriers to investment } \\
\text { activity in the Russian } \\
\text { Federation }\end{array}$ & $\mathbf{2 0 0 0}$ & $\mathbf{2 0 1 0}$ & $\mathbf{2 0 1 5}$ & $\mathbf{2 0 1 6}$ & $\mathbf{2 0 1 7}$ \\
\hline Investment risks & 35 & 23 & 60 & 50 & 51 \\
\hline Unsatisfactory technical base & 18 & 5 & 18 & 22 & 20 \\
\hline $\begin{array}{c}\text { Low profitability of } \\
\text { investments in fixed capital }\end{array}$ & 8 & 11 & 22 & 20 & 20 \\
\hline $\begin{array}{c}\text { Uncertainty of the economic } \\
\text { situation in the country }\end{array}$ & 49 & 32 & 66 & 61 & 57 \\
\hline
\end{tabular}




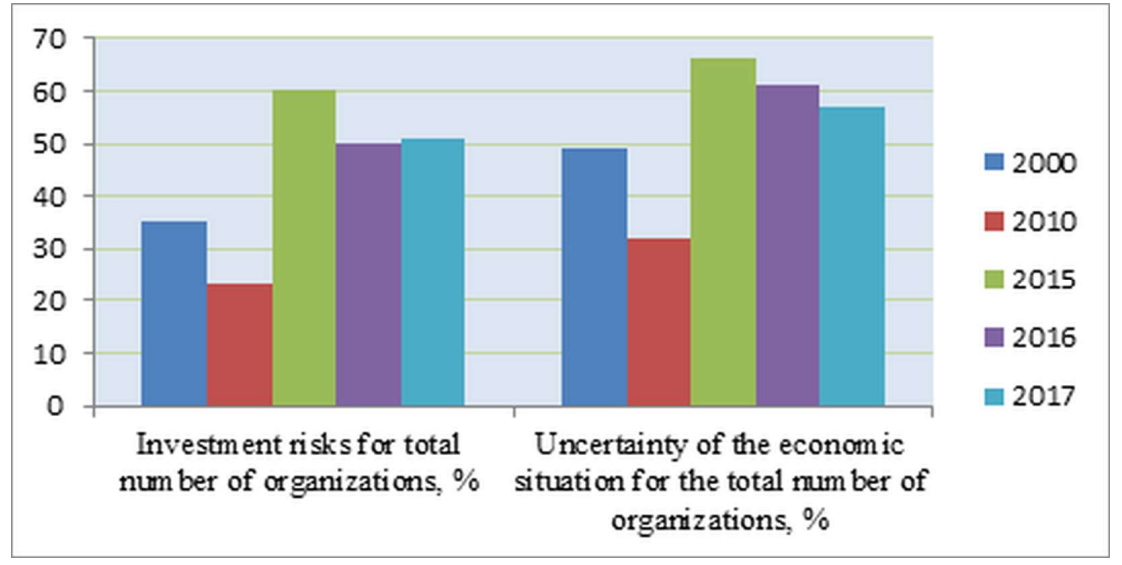

Fig. 2. The dependence of investment risks from the uncertainty of the economic situation (as a percentage of the total number of organizations).

The presented data allows to conclude that the higher the uncertainty of the economic situation in the country, the higher the investment risks, and the longer the investment cycle, the higher the degree of uncertainty of the planned results of the project - even during the pre-investment stage prices, exchange rates, demand on the company's products can change. In this case, the investment may be unjustified, and investors will suffer losses from their investments. This is one of the reasons why most investors are not willing to invest in long-term and risky projects, preferring less risky investments.

In the course of business, organizations generate risks of losses and damages, the size of which is associated with the specificity of the type of business activity. The main macroeconomic factors that cause risks in investment activities include: inflation and exchange rates, the situation in the mineral and raw materials markets, and the capital, equipment, materials and labor markets, government regulation. Along with the existing macroeconomic factors and the specific risks of mining companies, there are certain difficulties and risks of mining production that private investors in the exploration and mining industries face.

When evaluating investment projects in the mining industry, the following types of investment risks and uncertainties are the most significant:

- the risk of instability in economic legislation;

- the possibility of an economic and financial crisis in the country;

- foreign trade risks for organizations conducting foreign trade activities related to the possibility of imposing restrictions on the supply of goods;

- political risks and adverse socio-and-political changes in the country;

- fluctuations in market prices and exchange rates;

- natural and climatic risks;

- production risk - equipment breakdowns, accidents, etc.;

- invalidity or unavailability of the necessary information.

Since mineral deposits are hidden in the depths, it is not possible to determine their features, quantitative and qualitative characteristics with a sufficient degree of accuracy, which is necessary at the stage of development of an investment project as initial data. Therefore, the initial data in the design can only be determined approximately. Depending on the degree of such an approximation, the conformity of planned and actual indicators of investors' income and profits is determined further in the course of operation.

Specific man-made factors, such as mobility of groundwater, leaching of rocks, rock bursts and sudden destruction of rock massifs, deformations of quarries, explosions of 
methane-air mixtures in coal mines, fires in underground mine workings, etc. can lead to major accidents and even cause a halt in production (such cases have happened in the mines of the Kuznetsk, Pechora basins, etc.). Technogenic risks can have a significant impact on the activities of a mining enterprise and the amount of damage resulting from the implementation of an investment project. Taking into account the possible impact of natural and man-made risks at the project development stage allows us to predict the extent of possible damage as a result of natural and man-made disasters and take the necessary preventive measures to prevent significant financial losses for the investor.

Risks of lost profits for investors in the mining industry may appear at the stage of implementation of investment projects due to the development of new technologies in the exploration, extraction and processing of mineral raw materials, when funds have already been invested in outdated equipment, and reconstruction cannot lead to damage reduction.

For the valuation of risks at the stage of their identification, the probability of the occurrence of a particular risk is determined by the degree of their importance for investors by the method of expert assessments by ranking. Each project risk based on expert assessments is assigned a certain probability of its occurrence. Further, the amount of possible damage in terms of value is established for each risk. The integral indicator of the cost of risk assessment is determined by summing the products of the sum of possible losses $P$ by the probability of realization for each risk $B p(1)$

$$
\mathrm{Op}=\sum P * B p
$$

Thus, both general and specific risks affecting different stages of an investment project can be taken into account.

To analyze the factors of uncertainty and risk when evaluating the effectiveness of investment projects, a maximum of information about the conditions of the projects is used. Various methods can be used here: analysis of the sensitivity of the project to changes in factors; determination of the limit values of the project parameters; break-even point determination; adjustment of project parameters; building a decision tree; simulation modeling [4-7].

To assess investment risks for mining enterprises, we consider it expedient to use a simulation method that allows you to build models and evaluate risks in the implementation of large projects and minimize losses and damages. The basis of this method is systematization, the calculation of probability and damage, the multivariance of possible solutions and the assessment of the allowable costs of prevention and reserves. Risk is assessed in terms of value and time, and it is possible to take into account random effects and behavior.

Simulation modeling as a universal method of risk assessment has several advantages: it makes it possible to solve rather complex tasks and investigate complex systems; allows you to conduct research on the features of the functioning of a real system in various conditions, including critical, emergency, underground, etc.; makes it possible to reduce the cost and duration of tests compared with such methods as experiment, physical modeling, that is, allows to reduce the cost of resources.

A variation of the simulation method is the Monte Carlo method - a numerical method for solving mathematical problems using random variable modeling (this method was named after the city of Monte Carlo, known for its casinos, which uses roulette - the simplest mechanism for obtaining random numbers).

The main final indicator is VaR (Value at Risk) - the sum of the maximum losses in connection with investments for a certain period, based on calculations with a certain confidence interval. 
According to the results of all simulation experiments, a sample is formed, which is analyzed by statistical methods to obtain the probability distribution of the resulting indicator and calculate the main quantitative indicators of the project risk assessment.

A simulated VaR when making a management decision to invest with risk minimization must be compared with profitability indicators, as the main result of risk management efficiency. The current approach, according to the authors, is the use of risk-weighted performance indicators (Risk-Adjusted Performance Measure - RAPM), such as return on invested capital, risk-adjusted RAROC, modifications to EaR (risk returns) and EPaR (risk returns on equity) as well as risk-adjusted cash flow $\mathrm{CFa}$, etc.

Risk analysis using the Monte Carlo method is carried out in 3 stages: the construction of a mathematical model, the implementation of simulation and analysis of the results and their interpretation [8-10]. Based on these simulations, we can make predictions about the future of the project and offer recommendations on possible ways to reduce project risks.

\section{Conclusion}

Today, one of the factors constraining investment activity in the Russian economy is the presence of significant investment risks. The actual problem of mining companies is a thorough study of investment projects, risk assessment and investment risk management.

When developing specific measures to reduce investment risk and the uncertainty of obtaining planned economic results, one should consider the organization's ability to transfer risk to an insurance company; redistribution of risks between all participants of the investment project; self-insurance - creating reserve funds to cover unforeseen expenses and losses. Mitigation of risks in financing an investment project consists in achieving a positive balance of cash flows at each step of settlement. If possible, a guarantee system should be developed for the investor - from the state, banks, investment companies, etc. At all stages of investment risk management, one should strive to obtain additional reliable operational information. Summarizing, we note that the investment risk management system, which includes the process of its identification, measurement and evaluation, constitutes the main prerequisites and alternatives for actions to achieve the project's intended goals, analyze and prevent possible threats from not achieving the stated strategic or tactical goals of the mining enterprise.

\section{References}

1. Russia in numbers. 2017: A brief statistical compilation (ROSSTAT, Moscow, 2018)

2. V. Frolova, O. Dolina, T. Shpilkina, E3S Web Conf., 41, 04027 (2018)

3. Russian statistical yearbook - 2018 (ROSSTAT, Moscow, 2018)

4 S.A. Koshechkin, M.N. Dmitriev, Quantitative risk analysis of investment projects (Finance, Moscow, 2016)

5. M.N. Fedosova, A.M. Kornev Economics and Socium, 4:11, 846-853 (2014)

6. O. Kalenov, S. Kukushkin, E3S Web Conf., 41, 04025 (2018)

7. O. Kalenov, E. Shavina, E3S Web Conf., 41, 04054 (2018)

8. E. Dotsenko E., N. Ezdina, E3S Web = Conf., 41, 04048 (2018)

9. A. Kovalev, N. Rebrova, M. Zhidkova, E3S Web Conf., 41, 04026 (2018)

10. O. Borisova, V. Frolova, M. Livson, V. Biryukov, E3S Web Conf., 41, 04028 (2018) 